Tohoku J. exp. Med., 1974, 114, 49-54

\title{
In Vitro Production of a Chemotactic Factor by Inflammatory SH-Dependent Protease from Rabbit and Human Immunoglobulin G Subclasses
}

\author{
Shunsuke Yamamoto, Motoshi Nishiura and Katsumi \\ MATSUMURA \\ Department of Pathology, ${ }^{*}$ Kumamoto University Medical \\ School, Kumamoto
}

\begin{abstract}
Yamamoto, S., Nishiura, M. and Matsumura, K. In Vitro Production of a Chemotactic Factor by Inflammatory SH-Dependent Protease from Rabbit and Human Immunoglobulin $G$ Subclasses. Tohoku J. exp. Med., 1974, 114 (1), 49-54 Previously a chemotactic factor similar to an inflammatory factor (leucoegresin) was produced in vitro from natural IgG of man and rabbit by a neutral SHdependent protease from inflammatory tissue. The enzyme induced a similar chemotactic generation of $\operatorname{IgG}$ subclasses of man and rabbit. The generation of chemotactic substance was more pronounced from human $\operatorname{IgG}_{\mathrm{a}}$ and $\mathrm{IgG}_{4}$ or rabbit fast-moving $\operatorname{IgG}$ than from human $\operatorname{Ig} G_{1}$ and $I g G_{3}$ or rabbit slow-moving IgG. The results suggested that the enzyme activity was influenced by some particular structural specificity of IgG molecules. —_ leucocyte emigration; leucoegresin; chemotactic factor; protease; immunoglobulin $G$
\end{abstract}

As previously described (Hayashi 1967; Yoshida et al. 1968; Hayashi et al. 1969, 1974; Yoshinaga et al. 1971b), a chemotactic substance (leucoegresin) specific for polymorphonuclear (PMN) leucocytes has been considered to satisfy many criteria of the concept of inflammatory chemotactic factor. The substance was produced in vitro from rabbit IgG by a neutral SH-dependent protease from inflammatory tissue (Yoshinaga et al. 1970a, 1971a; Yamamoto et al. 1971); and it was thus considered that this neutral SH-dependent protease would act in turn on IgG molecules exuded after increase in vascular permeability as a substrate and change them to a chemotactic factor which causes the emigration of PMNs into the inflammatory lesion.

A similar chemotactic factor was generated in vitro from papain-resistant IgG subclasses of rabbit, mouse and man after treatment with papain, but not from papain-sensitive IgG subclasses, indicating that the production of chemotactic factors is associated with a structural specificity of IgG (Yoshinaga et al. 1972). The molecular size of the chemotactic factors produced in vitro was similarly about 140,000 , and closely resembled that of leucoegresin and untreated IgG when measured by gel filtration. It was further suggested that the chemotactic generation from IgG by the enzymes was associated with some minor structural change

Received for publication, July 25, 1974.

*Director: Prof. H. Hayashi. 
at the Fc portion of the molecule (Yamamoto et al. 1973).

The purpose of the present communication is to describe that the chemotactic generation by an inflammatory SH-dependent protease occurs from all the IgG subclasses tested, but its induction is more strong in papain-resistant IgG than in papain-sensitive IgG.

\section{Materials and Method}

\section{Estimation of chemotactic activity}

Chemotactic activity for PMN leucocytes was demonstrated by an in vitro assay according to a modification of Boyden's method (1962) using Millipore filters (DAWPO 13, pore size $0.65 \mu$; Millipore Filter Co., Bedford, Mass., U.S.A.). After incubation at $37^{\circ} \mathrm{C}$ for $3 \mathrm{hr}$, PMN leucocytes that had migrated through the filter were stained with haematoxylin and counted over five microscopic fields $(10 \times 40)$ randomly selected.

\section{Isolation of inflammatory SH-dependent protease II}

Following the previously described method (Koono et al. 1968), the inflammatory SH-dependent protease was extracted from the euglobulin fraction of 12 -hour-old Arthus lesions and then purified by chromatography using DEAE-Sephadex and GE-cellulose. The SH-dependent protease II eluted in $\mathrm{M} / 10$ phosphate buffer $(\mathrm{pH}$ 7.4) on GE-cellulose behaved as a homogeneous substance on electrophoresis. The optimum $\mathrm{pH}$ of the protease was 7.1. Concentrations of the protease solution were estimated by absorbancy at $280 \mathrm{~nm}$. Before use, the SH-dependent protease was activated by adding cysteine to a final con. centration of $1 \mathrm{mM}$.

\section{Estimation of protease activity}

The activity was measured in the presence of $1 \mathrm{mM}$ cysteine by a modification (Hayashi et al. 1962, 1965) of the casein digestion method of Kunitz (1947). The $\mathrm{pH}$ of the reaction was 7.1 and the ionic strength was 0.25 . After incubation at $37^{\circ} \mathrm{C}$ for $60 \mathrm{~min}$, an equal volume of $6 \%$ trichloroacetic acid was added to the reaction mixture and the mixture was filtered when precipitation was completed. The absorbance at $276 \mathrm{~nm}$ of the filtrate was measured and an arbitrary unit of proteolytic activity was defined as the amount of enzyme which would cause an increase of 0.001 unit of absorbance per min of digestion (Koono and Hayashi 1969). Accordingly, one proteolytic unit represents 0.06 absorbance unit at $276 \mathrm{~nm}$. Enzyme samples with proteolytic activity of $0.66 \mathrm{unit} / \mathrm{ml}$ were used.

\section{Preparation of immunoglobulin $G(I g G)$}

Rabbit IgG fraction was separated in the cold from normal rabbit serum according to the method of Kapusta and Halberstam (1964), using sodium sulfate and DEAE-cellulose column chromatography; fast-moving IgG was eluted in M/100 phosphate buffer ( $\mathrm{pH}$ 8.0) and slow-moving IgG in $\mathrm{M} / 200$ phosphate buffer ( $\mathrm{pH}$ 8.0). The isolated $\operatorname{IgG}$ was homogeneous as judged by immunoelectrophoresis with goat antiserum against rabbit serum (Yamamoto et al. 1971). Human IgG fraction was isolated from normal human serum by
the same method.

Human myeloma protein was harvested from a patient whose serum contained $5500 \mathrm{mg}$ IgG/ $100 \mathrm{ml}$ when measured by a single radial immunodiffusion technique (Fahey and Wunderlich 1964) using an immunoplate (Hyland Laboratories, Los Angeles, Calif., U.S.A.). The serum showed monoclonal IgG pattern by a microzone electrophoresis. From the serum, IgG fraction was isolated by the method of Kapusta and Halberstam (1964). The IgG fraction was eluted through a Sephadex G-200 column to eliminate any aggregated IgG. 
The fractionated IgG was homogeneous as judged by immunoelectrophoresis with rabbit antiserum against human serum. The molecular weight of the IgG was approximately 160,000. Each IgG fraction was dissolved in $\mathrm{M} / 15$ phosphate buffer, $\mathrm{pH} 7.4$, at a concentration of $200 \mu \mathrm{g} / \mathrm{ml}$.

TABLE 1. In vitro chemotactic generation from rabbit IgG by inflammatory $\mathrm{SH}$-dependent protease

\begin{tabular}{|c|c|c|c|}
\hline \multicolumn{3}{|c|}{ Samples in lower compartment } & \multirow{2}{*}{$\begin{array}{c}\text { Number of PMNs } \\
\text { migrating } \\
\text { (per } 5 \text { fields) }\end{array}$} \\
\hline $\begin{array}{l}\text { Rabbit IgG } \\
(\mu \mathrm{g})\end{array}$ & $\begin{array}{l}\text { Inflammatory protease } \\
\text { (proteolytic units) }\end{array}$ & $\begin{array}{l}\text { Cysteine } \\
\text { (in final) }\end{array}$ & \\
\hline Slow IgG* 100 & 0.33 & $1 \mathrm{mM}$ & 190 \\
\hline 100 & Buffer & Buffer & 29 \\
\hline Fast IgG $\dagger 100$ & 0.33 & $1 \mathrm{mM}$ & 280 \\
\hline 100 & Buffer & Buffer & 31 \\
\hline Buffert; & 0.33 & $1 \mathrm{mM}$ & 25 \\
\hline Buffer & Buffer & Buffer & 14 \\
\hline
\end{tabular}

The mixture of each sample $(0.5 \mathrm{ml})$ was incubated at $37^{\circ} \mathrm{C}$ for $60 \mathrm{~min}$ and placed in the lower compartment for assay of chemotactic potency.

* Eluted in $\mathrm{M} / 200$ phosphate buffer ( $\mathrm{pH} 8.0$ ) on DEAE-cellulose.

$\dagger$ Eluted in $\mathrm{M} / 100$ phosphate buffer $(\mathrm{pH}$ 8.0) on DEAE-cellulose.

$\ddagger \mathrm{M} / 15$ phosphate buffer $(\mathrm{pH}, 7.4)$.

TABLE 2. In vitro generation of chemotactic activity from normal human IgG and myeloma proteins by inflammatory $S H$-dependent protease

\begin{tabular}{|c|c|c|c|c|}
\hline \multicolumn{4}{|c|}{ Samples in lower compartment } & \multirow{2}{*}{$\begin{array}{c}\text { Number of PMNs } \\
\text { migrating } \\
\text { (per } 5 \text { fields) }\end{array}$} \\
\hline \multicolumn{2}{|c|}{$\begin{array}{l}\text { Human IgG and myeloma } \\
\text { IgG subclasses }(\mu \mathrm{g})\end{array}$} & Type & $\begin{array}{l}\text { Inflammatory protease } \dagger \\
\text { (proteolytic units) }\end{array}$ & \\
\hline \multirow[t]{2}{*}{ IgG* } & 100 & & 0.33 & 182 \\
\hline & 100 & & Buffer & 19 \\
\hline \multirow{4}{*}{$\operatorname{IgG} G_{1}$} & 100 & $\kappa$ & 0.33 & 140 \\
\hline & 100 & & Buffer & 27 \\
\hline & 100 & $\lambda$ & 0.33 & 140 \\
\hline & 100 & & Buffer & 23 \\
\hline \multirow{4}{*}{$\operatorname{IgG}_{2}$} & 100 & $\kappa$ & 0.33 & 259 \\
\hline & 100 & & Buffer & 20 \\
\hline & 100 & $\lambda$ & 0.33 & 252 \\
\hline & 100 & & Buffer & 30 \\
\hline \multirow{2}{*}{$\mathrm{IgG}_{3}$} & 100 & $\lambda$ & 0.33 & 115 \\
\hline & 100 & & Buffer & 34 \\
\hline \multirow[t]{2}{*}{$\mathrm{IgG}_{4}$} & 100 & $\kappa$ & 0.33 & 257 \\
\hline & 100 & & Buffer & 28 \\
\hline \multirow{2}{*}{\multicolumn{2}{|c|}{$\begin{array}{l}\text { Buffer* } \\
\text { Buffer }\end{array}$}} & & 0.33 & 15 \\
\hline & & & Buffer & 18 \\
\hline
\end{tabular}

The mixture of each sample $(0.5 \mathrm{ml})$ was incubated at $37^{\circ} \mathrm{C}$ for 60

min and placed in the lower compartment.

* Separated from normal human serum.

$\uparrow$ Activated in the presence of $1 \mathrm{mM}$ cysteine.

$\ddagger$ M/15 phosphate buffer (pH 7.4). 
RESULTS

In vitro generation of chemotactic activity from rabbit IgG by inflammatory $S H$ dependent protease

Each two samples $(100 \mu \mathrm{g})$ of fast- and slow-moving IgG were incubated with cysteine-activated $\mathrm{SH}$-dependent protease (0.33 units), as previously described (Yoshinaga et al. 1972). As summarized in Table 1, neither of the IgG samples showed the chemotactic effect on PMN leucocytes, but they acquired a chemotactic character after treatment with the enzyme, and its induction was clearly stronger in fast-moving IgG than in slow-moving IgG.

In vitro generation of chemotactic activity from human $I g G$ by inflammatory $S H$ dependent protease

Each IgG sample $(100 \mu \mathrm{g})$ was similarly treated with cysteine-activated SHdependent protease (0.33 units). Two samples of $\operatorname{IgG}_{1}$, two samples of $\operatorname{IgG}_{2}$, two samples of $\mathrm{IgG}_{3}$ and one sample of $\mathrm{IgG}_{3}$ were treated. As shown in Table 2, samples of myeloma IgG subclasses did not show any chemotactic activity for PMN leucocytes, but became chemotactic after treatment with the enzyme; the chemotactic induction of $\operatorname{IgG}_{2}$ and $I g G_{4}$ was apparently stronger than that of $I_{g G_{1}}$ and $\mathrm{IgG}_{3}$.

\section{Discussion}

As previously reported (Yoshinaga et al. 1972; Hayashi et al. 1974), a chemotactic generation of IgG by mild digestion of papain $(0.33$ units) was found positive only for papain-resistant IgG; it included rabbit fast-moving IgG, human $\mathrm{IgG}_{2}$ and $\mathrm{IgG}_{4}$, and mouse $\mathrm{IgG}_{1}$. In contrast, papain-sensitive IgG such as rabbit slow-moving $\operatorname{IgG}$, human $\operatorname{IgG}_{1}$ and $\operatorname{IgG} G_{3}$, and mouse $\operatorname{IgG}_{2 \mathrm{a}}$ and $\operatorname{IgG}_{2 \mathrm{~b}}$ were completely negative under the same conditions. Accordingly, these observations suggested that generation of chemotactic activity from IgG molecules by treatment with papain was apparently associated with their susceptibility to the enzyme, namely the specificity of heavy chain structure of the IgG molecule.

The observations presented here demonstrated that the inflammatory SHdependent protease at the same activity $(0.33$ units) also induced chemotacitc generation of IgG subclasses of rabbit and man with some (but not apparent) relation to a particular structural specificity of the IgG molecule. Although all the IgG assayed became chemotactic after treatment with the enzyme, the generation of chemotactic activity from papain-resistant $\operatorname{IgG}$ of rabbit and man was stronger than that from papain-sensitive IgG. Such results, however, seemed to suggest an underlying process in the production of leucoegresin in inflammatory leucotaxis in man and animal.

As demonstrated previously, the enzymatic condition favorable to chemotactic generation from IgG molecules was a mild treatment with a small amount $(0.33$ units) of an inflammatory SH-dependent protease and papain. Similar results were 
obtained with water-insoluble papain (free of cysteine) (Yoshinaga et al. 1970b). The enzymatic digestion of IgG with papain in short duration or with waterinsoluble papain has been shown to produce some intermediate products similar to IgG in untreated molecular size (Cebra et al. 1961; Nelson 1964; Jefferis and Stanworth 1967). The intermediate products may be cleaved enzymatically in the successive steps leading to production of Fab and Fc fragments, and then the chemotactic effect may be abolished; this will present a reasonable explanation of chemotactic induction of papain-resistant IgG.

On the other hand, the inflammatory SH-dependent protease did not produce Fab and Fc fragments even after a long-term digestion. The chemotactic generation was accompanied only by a release of dialysable peptides from the IgG molecule (Yamamoto et al. 1973). This may explain chemotactic induction of all the IgG assayed, though the reason for some difference in the chemotactic generation is still obscure.

\section{Acknowledgments}

We are greatly indebted to Prof. H. Hayashi for his invaluable instruction and revision of this manuscript, and Dr. M. Giesen at Central Laboratory of Blood Transfusion, Amsterdam, The Netherlands, and Dr. Y. Kinuwaki at Kumamoto National Hospital, Kumamoto, for their generous supply of the sera. The work was in part supported by grants from the Mitsubishi Foundation, Tokyo and the Society for Metabolism Research, Tokyo, which were given to Prof. H. Hayashi.

\section{References}

1) Boyden, S. (1962) The chemotactic effect of mixtures of antibody and antigen on polymorphonuclear leucocytes. J. exp. Med., 115, 453-466.

2) Cebra, J.J., Givol, D., Silman, H.I. \& Katchalski, E. (1961) A two-stage cleavage of rabbit $\gamma$-globulin by a water-insoluble papain preparation followed by cysteine. J. biol. Chem., 236, 1720-1725.

3) Fahey, J.L. \& Wunderlich, J. (1964) The immunoglobulin of mice. J. exp. Med., 120, 243.

4) Hayashi, H. (1967) Mechanism of development and inhibition of inflammatory process. Trans. Soc. Path. Jap. (Jap.), 56, 37-63.

5) Hayashi, H., Koono, M., Yoshinaga, M. \& Muto, M. (1969) The role of an SHdependent protease and its inhibitor in Arthus-type hypersensitivity reaction, with special reference to chemical mediation of increased vascular permeability and leucocyte emigration. In: Inflammation Biochemistry and Drug Interaction, edited by A. Bertelli \& J.C. Houck, Excerpta Medica Foundation, Amsterdam, pp. 34-52.

6) Hayashi, H., Miyoshi, H., Nitta, R. \& Udaka, K. (1962) Proteolytic mechanism in recurrence of Arthus-type inflammation by thiol compounds. Brit. J. exp. Path., 43, 564-573.

7) Hayashi, H., Udaka, K., Miyoshi, H. \& Kudo, S. (1965) Further study of correlative behavior between specific protease and its inhibitor in cutaneous Arthus reaction. Lab. Invest., 14, 665-673.

8) Hayashi, H., Yoshinaga, M. \& Yamamoto, S. (1974) The nature of a mediator of leucocyte chemotaxis in inflammation. In: Chemotaxis, Its Biology and Biochemistry, edited by E. Sorkin, S. Karger, Basel, pp. 296-332.

9) Jefferis, R.\& Stanworth, D.R. (1967) Structural differences within the gamma G class of immunoglobulins. Nature (Lond.), 215, 267-277. 
10) Kapusta, M.A. \& Halberstam, D. (1964) Purification of pure $7 \mathrm{~S} \gamma$-globulin. Biochim. biophys. Acta (Amst.), 93, 657-659.

11) Koono, M. \& Hayashi, H. (1969) Purification of inflammatory SH-dependent proteases I and II from Arthus skin lesion and their significance in inflammatory changes. Jap. J. Biochem. Soc. (Jap.), 41, 436.

12) Koono, M., Muto, M. \& Hayashi, H. (1968) Protease associated with Arthus skin lesions: their purification and biological significance. Tohoku J. exp. Med., 94, 231-235.

13) Kunitz, M. (1947) Crystalline soybean trypsin inhibitor. II. General properties. $J$. gen. Physiol., 30, 291-310.

14) Nelson, C.A. (1964) Isolation of a new intermediate in the papain cleavage of rabbit $\gamma$-globulin. J. biol. Chem., 239, 3727-3732.

15) Yamamoto, S., Nishiura, M. \& Hayashi, H. (1973) The natural mediator for PMN emigration in inflammation. $V$. The site of structural change in the chemotactic generation of immunoglobulin $G$ by inflammatory SH-dependent protease. Immunology, 24, 791--801.

16) Yamamoto, S., Yoshinaga, M. \& Hayashi, H. (1971) The natural mediator for PMN emigration in inflammation. II. Common antigenicity of leucoegresin with immunogloublin. G. Immunology, 20, 803-808.

17) Yoshida, K., Yoshinaga, M. \& Hayashi, H. (1968) Leucoegresin: a factor from rabbit skin associated with leucocytic emigration in the Arthus reaction. Nature (Lond.), 218, 977-978.

18) Yoshinaga, M., Mayumi, M., Yamamoto, S. \& Hayashi, H. (1970a) Immunoglobulin G as possible precursor of chemotactic factor. Nature (Lond.), 225, 1138-1139.

19) Yoshinaga, M., Yamamoto, S., Kiyota, S. \& Hayashi, H. (1970b) Behavior of PMN leucocytes in microcirculation and mechanism of chemotaxis. Saishin Igaku (Jap.), 25, 1641-1652.

20) Yoshinaga, M., Yamamoto, S., Kiyota, S. \& Hayashi, H. (1972) The natural mediator for PMN emigration in inflammation. IV. In vitro production of a chemotactic factor by papain from immunoglobulin G. Immunology, 22, 393-399.

21) Yoshinaga, M., Yamamoto, S., Maeda, S. \& Hayashi, H. (1971a) The natural mediator for PMN emigration in inflammation. III. In vitro production of a chemotactic factor by inflammatory SH-dependent protease from serum immunoglobulin G. Immunology, 20, 809-815.

22) Yoshinaga, M., Yoshida, K., Tashiro, A. \& Hayashi, H. (1971b) The natural mediator for PMN emigration in inflammation. I. Purification and characterization of leucoegresin from Arthus skin site. Immunology, 21, 281-298. 